\title{
Tradition, Modernity and Authenticity of Architecture in China and Japan During the 20th Century
}

\author{
Zeyang Yu
}

\begin{abstract}
With the globalization, China and Japan had struggled how to handle the relationship between tradition and modernity. The process of modernity also leads to the questioning of "authenticity" in their architecture. This essay evaluates the relationship of tradition, modernity and authenticity in these countries, based on the essence and form, during the 20th century.
\end{abstract}

Index Terms-Tradition, modernity, authenticity, architecture.

\section{INTRODUCTION}

In the past century, China and Japan have undergone the process of modernization, which based on the western culture, with the globalization. Because of the regional and cultural differences, it is impossible to apply stereotype of western architecture to imbue in the local buildings. The tradition and modernity of architecture in these countries seem take the opposite side in the 20th century [1]. However, both of them try to maintain their tradition while combine the modernity with them, there also can find examples which show the coexistence between tradition and modernity in harmony. This complicated situation leads a question - what is the authenticity of architecture in these countries? This essay evaluates the development of tradition and modernity in China and Japan based on the essence and form while attempt to find the relationship of tradition, modernity and authenticity in these countries during the past century.

\section{THE PROCESS OF MODERNITY IN CHINA AND JAPAN}

At the end of the 19th century, the second industrial revolution triggered the process of globalization. "Fig. 1" As the western culture expanded all over the world, the regional cultures of China and Japan were threatened by westernization [2]. The main architectural style, which spreads all over the world, was colonial veranda style at that time "Fig. 2". It was the main architectural style in these two countries. The traditional regional buildings were replaced in a short time. Facing this change, the reactions of China and Japan follow four steps: resisted, adopted, reused and transformed [3]. The architecture in these countries tend to find a way which can combine the modernity with regional identity. However, they had failed as they blindly applying traditional symbols to generate a regional style while neglect the essence and form which represent the authenticity.

Manuscript received February 23, 2018; revised April 9, 2018.

Zeyang $\mathrm{Yu}$ is with the Huazhong University of Science and Technology, China (e-mail: yzy_eric@hotmail.com).

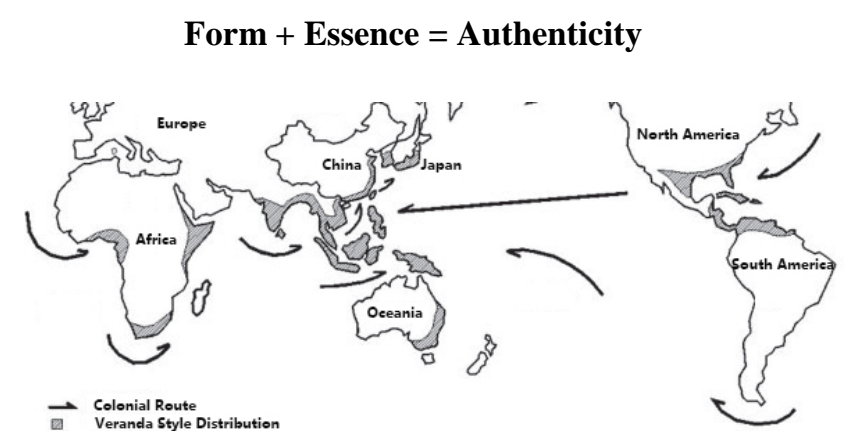

Fig. 1. The Colonial Route and Veranda Style Distribution.

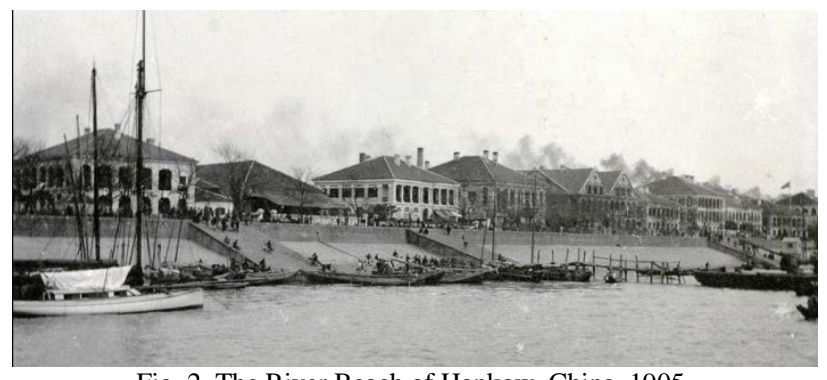

Fig. 2. The River Beach of Hankow, China, 1905.

\section{A. The Process of Modernity in China}

Since the Opium War in 1840, the urban-scape especially the architectures in many big cities in China were characterized by western architects. They have introduced different architectural styles in this country which include colonial veranda style, western classical style, art-deco style and so on. All of them are represent the western culture and have no connection with the local humanistic environment. Some western architects aware this problem and tried to resolve it, they intend to combine the traditional elements with western architectural styles, however, as they do not understand the Chinese traditional culture, these attempts failed finally "Fig. 3\&4". As the first generation of Chinese architects who had trained overseas entered the scene around 1910s, the Beaux Arts system, which reflects the formalist, historicist and eclectic of nineteenth- century European architecture, had started to influence Chinese architecture in many ways which lasted the whole century [3]. In order to prevent the rapid decline of the traditional Chinese architecture and restore the traditional culture, there arose a movement which called the 'Chinese Form' [3]. And from 1920s to 1950s, there have two types of Chinese Form which were caused by nationalists and communists [4]. The most important feature of them is the Chinese style roof with a modern structure [5]. This kind of building which combined native traditional elements with Beaux Arts should signaled as a new Chinese architecture. Furthermore, 
these kinds of movements, which juxtapose regional identity with modernized, tried to get a balance between tradition and modernity through $\mathrm{Ti}$ (essence) and Yong (form). However, as their absence of reference to tradition and modernity, this kind of architecture cannot be understood as both of them [6]. After 1976, architects in China are more interested in tradition and history, and have a tendency to resist the modernism [7]. They want to embrace the essence without understanding varieties of tradition, which usually leads to a blurring of the past. The preservation program of historical buildings in Shanghai is an example. It appears to be positive as the historical buildings represented the symbolism of the past Shanghai. When the condition changed, the historical buildings gradually faded into the modern buildings and the function of this program was lost [8]. In other words, the treatment of tradition should be taken care of. Fortunately, during the 1990s, as the reform and opening, architects found ways to make the cultural tradition fuse with modernization in harmony. The TEDA "Fig. 5" in Tianjin, which refers to the layout of "Kao Gong Ji" "Fig. 6", is an example to show the combination of traditional Chinese elements into a modern project successfully [9]. The common features of Chinese ancient cities should follow this description: "outer and inner sets of walls and gates, the clearly articulated spaces, implementation of a sort of rid pattern, the direction of movement along major north-south and east-west axes, the centrality of imperial sectors, and the existence of prescribed ceremonial places [10]." The plan of TEDA follows the rule of "Kao Gong Ji" and takes some modifications to meet the requirements of modern society. It can be considered a way to keep the balance between the tradition and modernity.

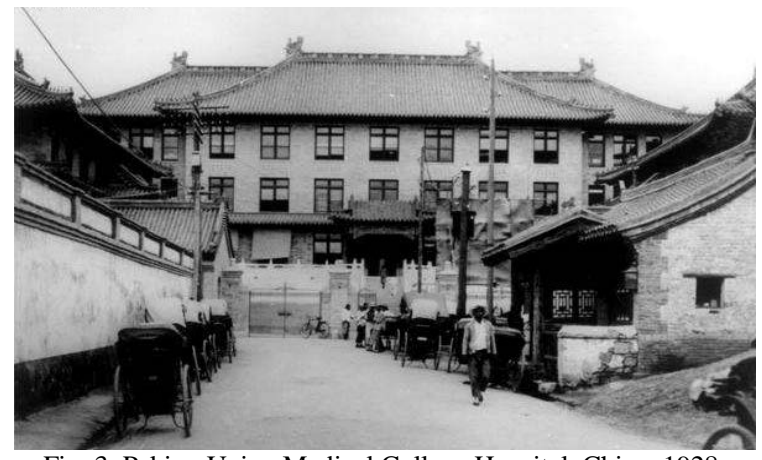

Fig. 3. Peking Union Medical College Hospital, China, 1928.

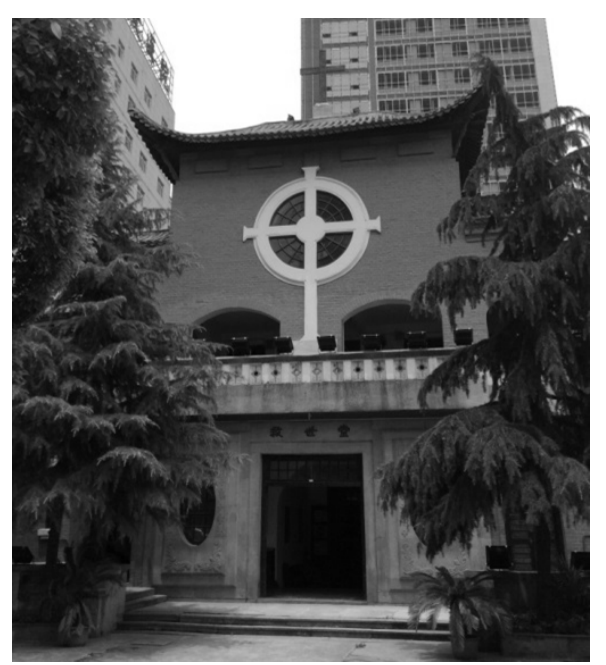

Fig. 4. The Salvation Church, Hankow, China, 1930.

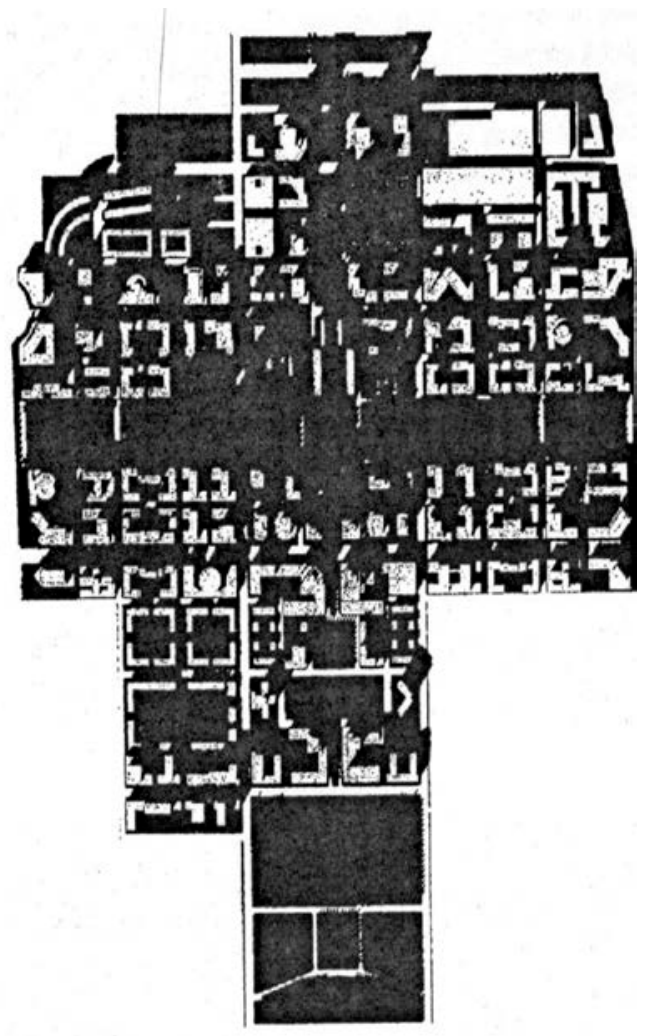

Fig. 5. The plan of TEDA.

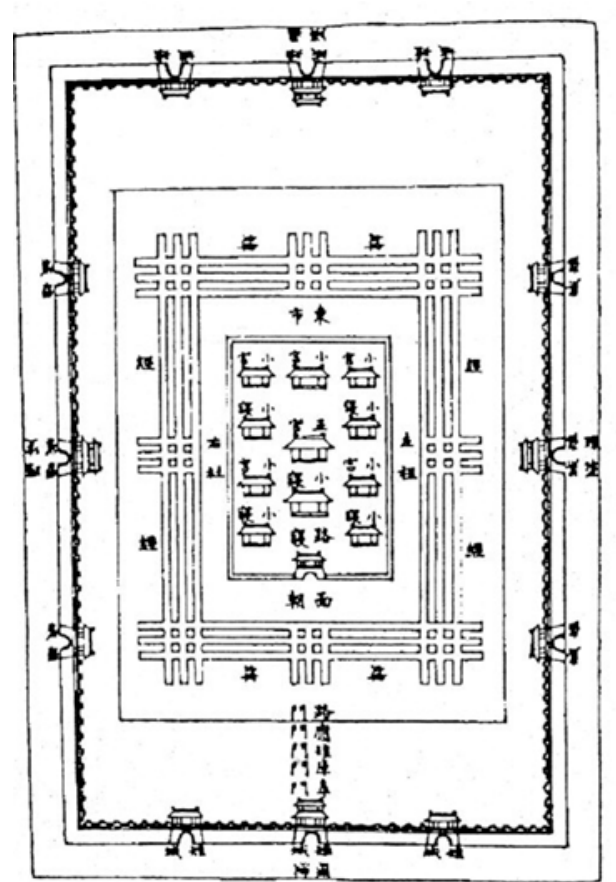

Fig. 6. The layout of a traditional Chinese city.

\section{B. The Process of Modernity in Japan}

Japan is also influenced by western culture after the industrial revolution. The conception of 'modernizing' caused the consideration between the internationalism and regionalism [11], which also reflects to the form and essence of architecture in Japan. The architects in Japan have different concepts on architectural design especially the identity of a building, whereas all of them tried to combine the traditional with modernity. Through the designs of a Japanese architect, which was thought as the representative of the period between 1920s and 1950s, people are able to realize the relationship between tradition and modernity at 
that time. Yoshida, a Japanese architect who was a pioneer in the modern style of building in that period. He chose to modify and update the Sukiya "Fig. 7", which is derived from teahouse construction in the sixteenth-century, with modern style "Fig. 8”. As he said: “Among traditional Japanese architecture, the Sukiya is the closest in concept to modern structures, and I thought was the easiest means to modify for the present lifestyle [11].” Although people can feel the tradition and regional essence with the Sukiya style, as he mixed the western lifestyle with traditional facilities in his design, it is understood that Yoshida's Sukiya was genuinely modern [11]. Clearly, the form is traditional, but the essence cannot eliminate the effects of western culture, the architecture is still considered as modern. After the World War II, culture and peace were the main leitmotif of Japan [12]. As Japan held the World Design Conference and the Metabolism group came into being, there created new conceptions of modernity in this country "Fig. 9". The theory of Metabolism group is an example, whereby the modern architecture is analogous to living things, which updates the theory of Le Corbusier: "a house is a machine to live in" [4], [5]. This is quite different from the original concept of modernism, which was formed at the beginning of the twentieth century. It seems that Japan has kept the pace with western countries especially with new conceptions As the country was affected by economic growth, the commercial theories managed the nation [13]. Western culture has deep influences with this country, as the local Japanese people were more likely to chase high technology. Japan had fewer opportunities to show its own will clearly. Tradition was not important to the country as before.

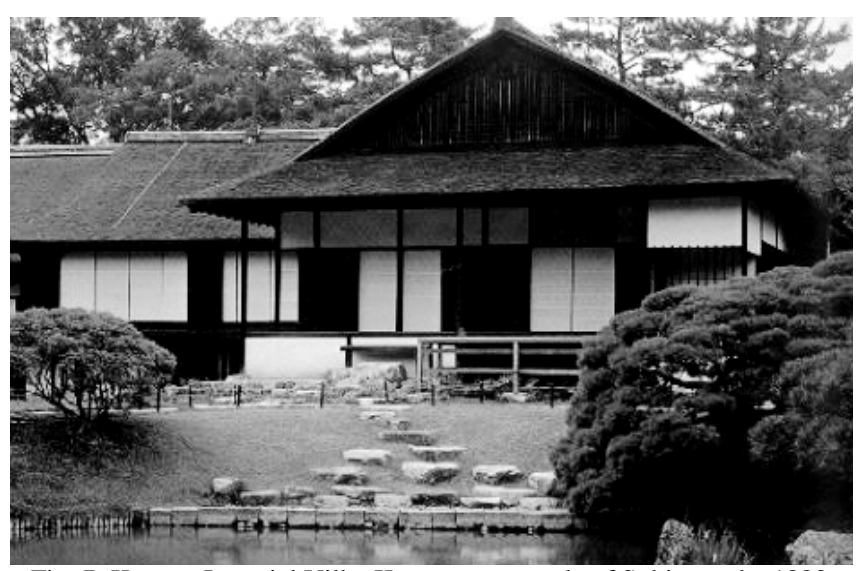

Fig. 7. Katsura Imperial Villa, Kyoto, an example of Sukiya style, 1883.

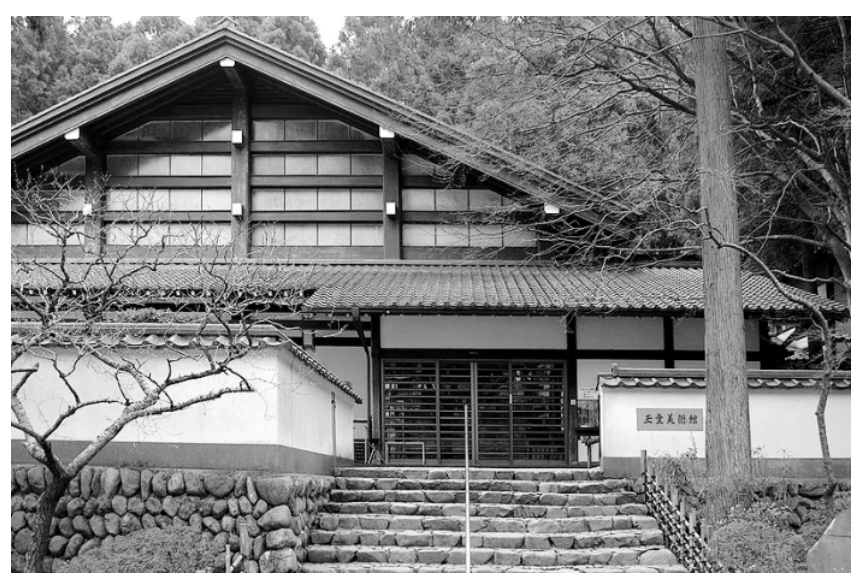

Fig. 8. Isoya Yoshida, Gokudo Art Museum, 1960.

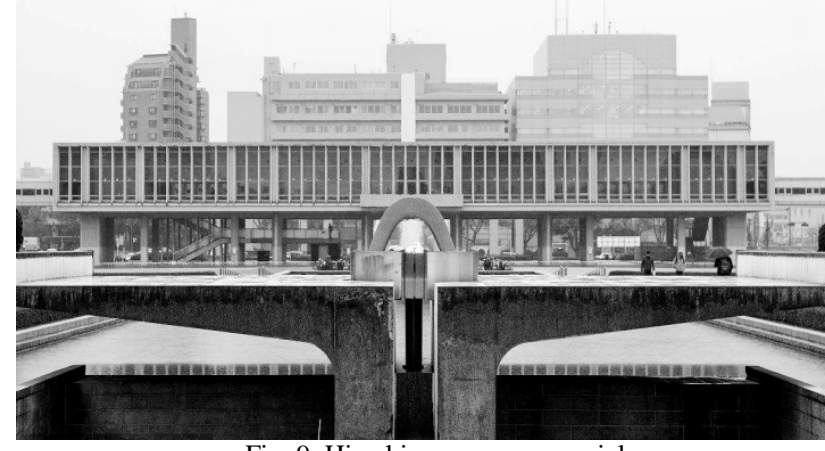

Fig. 9. Hiroshima peace memorial

Through the development of architecture in China and Japan in the first half of 20th century, it can find both China and Japan deliberately manipulated the relationship between tradition and modernity, thus present a civilized image of modernization to the west countries. For China, it is almost related to the political events like the May Fourth Movement. For Japan, on the other hand, was mostly influenced by economy. However, when these two countries tend to take the "western model" from the developed countries, they have lost their regional identities gradually. Fortunately, in the second half of 20th century, the contemporary architecture in China and Japan achieve a delicate balance between tradition and modernity, which tend to acknowledge not only the historical elements, but also the modern context. The essence of tradition is to be handled with care while the form is modernized to fit the contemporary aesthetical standard.

\section{NEW ATTEMPTS BY CONTEMPORARY ARCHITECT}

With the development of science and technology, the conception of architectural design and the technology of building construction have a great progress nowadays. Therefore, there appeared some new architecture schools such as modernism, deconstructionism and so on. Some of them have abandoned the tradition completely. Both China and Japan, which have thousand years civilization history, join in the stream. In a period, this kind of building with new form has occupied the corners of cities in these countries. For instance, in Beijing, the capital of China, lots of "special" buildings have been built and are famous as their unique modeling, firmness has been replaced by fluid. It seems that only this kind of building can represent the modernity.

However, this kind of observation and thinking might not be advisable. As the excessive pursuit of architecture form which leads by new conceptions, they are meaningless as they do not have connections with local environment. In this kind of building, people may not get the same feeling as Kenzo Tang and Noboru Kawazoe described: "Here primeval darkness and eternal light, the vital and the aesthetic, are in balance, and a world of harmony with nature [14]." Furthermore, because of the new architectural form, there do not have enough theories or instruments to support the idea, they are more likely to rely on the imagination. Colin Rowe and Fred Koetter in their essay 
“Collage City” questioned the concentration of modernism supported by the realization of future and idealized environment [15]. Therefore, architects abandon the tradition and regional culture is not a mature idea.

\section{CONCLUSION}

In modern period, the trend of globalization with the "western model" is an unavoidable historical fact. Compare the process of modernity in China and Japan, it can find that they were deeply influenced by western culture from the 19th century. Both of them have taken action to resist the threat of westernization. The main solution is keeps the essence and form of tradition and transform them into modernity. However, the process of transform blurs the boundary between tradition and modernity in China and Japan, which lead these two countries loss their regional identity gradually "Fig. 10". It can be considered that the modernity assimilates the tradition or the reverse is also true, but it is hard to define the authenticity of architecture in China and Japan nowadays.

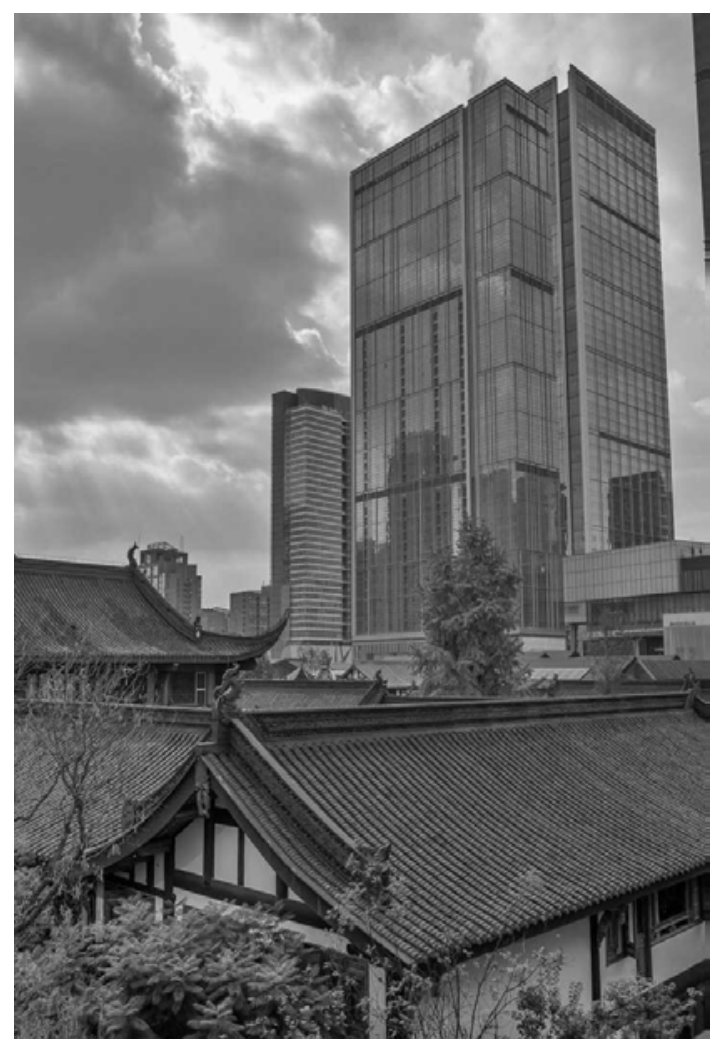

Fig. 10. Tradition and Modernity.
Taking a view of the present situation of the global architecture, the trend still exists. The pluralistic development of human history and civilization is uniformed by economic and political forces, which is leaded by the developed countries, into a single direction. Globalization has dominated present society. How to keep the tradition in developing country is still need be concerned.

\section{REFERENCES}

[1] H. Yatsuka, "At the end of the century: One hundred years of architecture,” Architecture, vol. 87, no. 9, pp. 167-168, 1998.

[2] K.T. Ravindran, "Contemporary architecture: An uncomfortable glance at the mirror,” Architecture + Design, vol. 14, no. 1, p. 27, Jan.-Feb. 1997.

[3] J. Zhu, "Beyond revolution: Notes on contemporary Chinese architecture,” Aa files, vol. 35, pp.3-14, 1998.

[4] P. G. Rowe, "Modernization in China," AV Monographs, vol. 109110, no. 9-12, pp.17, September-December 2004.

[5] J. Zhu, "Beyond revolution: Notes on contemporary Chinese, Architecture,” Aa files, vol. 35, pp. 3-14, 1998.

[6] P. G. Rowe, "Modernization in China," AV Monographs, vol. 109110, no. 9-12, pp.17, September-December 2004.

[7] J. Zhu, "Beyond revolution: Notes on contemporary Chinese architecture,” Aa files, vol. 35, pp.3-14, 1998.

[8] A. Abbas, "Play It Again Shanghai: Urban Preservation in the Global Era," in Shanghai Reflections: Architecture, Urbanism, and the Search for an Alternative Modernity, Mario Gandelsonas, Ed. New York: Princeton Architectural Press, 2002, pp. 48-49.

[9] A. C. Coombes, "Mass and void in the people’s republic," $2 G$, vol. 2, no. 2, pp. 116-118, 1999.

[10] N. S. Steinhardt, "Why were Chang'an and Beijing so different?" Journal of the Society of Architectural Historians, vol. 45, no. 4, pp. 339-357, 1986.

[11] H. Yatsuka, "At the end of the century: One hundred years of architecture,” Architecture, vol. 87, no. 9, pp. 167-168, 1998.

[12] H. Suzuki, Contemporary Architecture of Japan 1958-1984, London: The Architectural Press, 1985, pp. 5-7.

[13] A. Isozaki, "Of City, Nation, and Style," in Postmodernism and Japan, Durham: Duke University Press, 1989, p. 52.

[14] K. Tange and N. Kawazoe, Ise: Prototype of Japanese Architecture, Cambridge: The MIT Press, 1965, p. 52.

[15] A. Forty, "Memory," in Words and Buildings: A Vocabulary of Modern Architecture, London: Thames \& Hudson, 2000, p. 218.

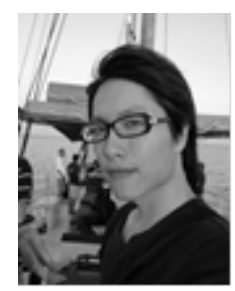

Zeyang Yu was born in China. He took the master degree of architecture in UNSW(2011-2012), Sydney, Australia, and now he is a Ph.D candidate of architecture in HUST(2014-Present), Wuhan, China. He has worked in the CITIC General Institute of Architectural Design and Research Co.,Ltd during 2012-2014 as an associate architect. He has published an essay, which name is "From the research of modern architect's life experience to the transformation of architecture's style and features in the modern city - Base on case analysis of the founder of Hemmings \& Berkley” in the magazine of Architect(China). 